\title{
O abrigo para crianças e adolescentes: considerações acerca do papel do terapeuta ocupacional*
}

\section{The shelter for children and adolescents: considerations on the role of the occupational therapist}

\author{
Sandra Maria Galheigo ${ }^{(1)}$
}

\begin{abstract}
GALHEIGO, S.M. O abrigo para crianças e adolescentes: considerações acerca do papel do terapeuta ocupacional. Rev. Ter. Ocup. Univ. São Paulo, v. 14, n. 2, p. 85-94, maio/ago. 2003.

RESUMO: Este artigo é uma reflexão acerca do papel do terapeuta ocupacional nos abrigos para crianças e adolescentes. Apresenta o abrigo como medida de proteção estabelecida pelo Estatuto da Criança e do Adolescente (ECA) e como equipamento de proteção social cuja proposta de ação e dinâmica de atendimento ainda têm muito por se construir. Com tal propósito realiza uma retrospectiva da atenção ao abandonado no Brasil desde a época colonial, apresenta as mudanças trazidas pelo ECA e reflete acerca das demandas para o trabalho com a população abrigada. Propõe também a tecer considerações sobre as diversas ações que o terapeuta ocupacional pode desenvolver e levantar as situações-limite que precisam ser superadas.
\end{abstract}

DESCRITORES: Terapia ocupacional/tendências. Constituição e estatutos. Abrigo. Criança institucionalizada. Adolescente institucionalizado.

\footnotetext{
* Trabalho apresentado como tema livre no VIII Congresso Brasileiro de Terapia Ocupacional e V Congresso Latino-Americano de Terapia Ocupacional, realizado em Foz do Iguaçu, Paraná, de 2 a 6 de junho de 2003.

${ }^{(1)}$ Professora Titular da Faculdade de Terapia Ocupacional da Pontifícia Universidade Católica de Campinas, PUC-Campinas. Doutora em Ciências Sociais pela Universidade de Sussex, Reino Unido. Coordenadora do Núcleo Campinas do Projeto Metuia.

Endereço para correspondência: Profa.Sandra Maria Galheigo, Faculdade de Terapia Ocupacional, Centro de Ciências da Vida, PUC-Campinas, Av. John Boyd Dunlop, s/nº Jardim Ipaussurama, 13.059-740, Campinas, SP, e-mail: sandramg@terra.com.br.
} 


\section{INTRODUÇÃO}

$\mathrm{O}$ Estatuto da Criança e do Adolescente (ECA) inaugurou um novo olhar e tratamento às questões da infância e da juventude. Ao regulamentar a aplicação das medidas sócio-educativas e de proteção, leva ao estabelecimento de políticas de atendimento variadas. As medidas de proteção previstas no ECA, hierarquicamente estabelecidas, prevêem, em caso de omissão, abuso ou extremada impossibilidade da família em cuidar de seus filhos, o encaminhamento para famílias substitutas e, na falta destas, para abrigos. Estes, de caráter temporário, vêm substituir as unidades de internação das Fundações Estaduais do Bem-Estar do Menor (FEBEMs), conhecidas pelo seu caráter asilar, massificador e excludente. Em oposição a tais práticas, espera-se que a política de abrigamento, agora sob responsabilidade municipal, seja implementada por organizações governamentais ou não-governamentais que possam oferecer um ambiente parecido com o familiar, com um número pequeno de abrigados e um conjunto de cuidadores em número suficiente, com perfil e preparação técnica adequados. Apesar de muitas iniciativas já serem oferecidas neste sentido, a dinâmica institucional dos abrigos em geral ainda necessita ser re-pensada caso se pretenda efetivamente romper com o modelo anterior. O terapeuta ocupacional, cuja experiência no campo social ainda é limitada, tem sido convidado a se juntar a tais iniciativas, deparando-se com circunstâncias desafiadoras para as quais não se encontra suficiente preparado.

O abrigo é uma das medidas de proteção especial previstas no artigo 101 do Estatuto da Criança e do Adolescente (ECA). Na medida em que o ECA também define princípios para a implementação de programas desenvolvidos por entidades que ofereçam tal medida, o abrigo acaba por se configurar, de fato, como um novo equipamento de ação (proteção) social. Ele surge, portanto, sob a expectativa de expurgar do cenário brasileiro a figura das instituições asilares para crianças e adolescentes, alvo de debate e crítica nas últimas três décadas. O próprio ECA, embora promulgado em 13 de julho de 1990, encontra-se ainda em fase de implantação já que se propõe a efetuar mudanças radicais na atenção à criança e ao adolescente; mudanças estas demoradas por demandarem a desconstrução de práticas enraizadas na perspectiva da remediação assistencialista ao invés de fundadas nos princípios do direito.

O cumprimento às determinações do ECA têm levado à percepção da necessidade de se profis- sionalizar a atenção nos abrigos, substituindo a prática da caridade que visa a simples manutenção da sobrevivência por uma ação conseqüente de caráter efetivamente protetor. Isto é, pretende-se que além de um espaço de acolhimento e cuidado que substitua o da família, o abrigo também promova a (re)-construção dos laços afetivos, a elaboração das situações de sofrimento psíquico que vislumbre a possibilidade de uma vida plena e saudável.

A situação dos abrigos, contudo, ainda é precária seja em seus recursos materiais ou humanos. Começam a surgir iniciativas que buscam uma atenção alternativa e que têm se preocupado com uma política de recursos humanos que preveja a contratação criteriosa, a capacitação de cuidadores, educadores e técnicos e a construção de projetos com ações programáticas claramente delineadas. Entretanto, sua divulgação ainda pequena, ficando restrita ao domínio do município que a desenvolve.

Os profissionais que se vêem envolvidos em trabalhos com abrigos têm buscado compreender seu papel neste novo cenário político. Em contrapartida, eles o fazem em um momento que a interdisciplinaridade tem apagado os contornos que definiam anteriormente seus papéis profissionais. Se tal fenômeno é um ganho tanto para o processo de produção do conhecimento como para a construção de uma ação mais integrada de caráter transdisciplinar, ele igualmente pode se manifestar ameaçador na medida em que acaba por deflagrar as desgastadas incursões corporativistas, num campo ainda marcado por práticas conservadoras.

É neste contexto que o terapeuta ocupacional vêm se agregar. Na escassez de balizamentos e práticas que norteiem sua ação e enfrentando o desconhecimento de sua contribuição por profissionais do campo social e gestores de entidades, ele tem arduamente buscado um eixo em torno do qual ele venha construir sua prática.

Este artigo se propõe, portanto, apresentar uma retrospectiva da atenção ao abandonado no Brasil, as mudanças trazidas pelo ECA e as demandas para o trabalho com a população abrigada. Propõe-se também a tecer considerações sobre as diversas ações que o terapeuta ocupacional pode desenvolver e levantar as situações-limite que precisam ser superadas. Partindo do pressuposto que a constituição de um campo de conhecimento e prática "organiza-se em torno de um eixo que compreende um recorte macro-estrutural, histórico e conceitual, um domínio político-operacional e um elenco de ações dirigidas ao domínio pessoal e coletivo" (GALHEIGO, 1999), ele buscará percorrer este caminho para situar o trabalho nos abrigos e a 
participação potencial que o terapeuta têm a oferecer. Para a consecução de tal objetivo, a autora faz uso de dados obtidos em pesquisa bibliográfica e documental sobre políticas para a Infância e a Adolescência (GALHEIGO, 1996) e sobre o trabalho em abrigos, em pesquisa sobre a rede de atenção à criança e ao adolescente de Campinas (GALHEIGO, 2003), e da experiência enquanto docente da disciplina de Prática Terapêutica Supervisionada II da Faculdade de Terapia Ocupacional da PUC-Campinas, quando responsável por projetos desenvolvidos em dois abrigos deste município, nos anos de 1999 (GALHEIGO, 1999a) e 2002 (GALHEIGO, 2002).

\section{Da internação ao abrigo: os caminhos da proteção à infância abandonada no Brasil}

A medida de proteção chamada de abrigo em entidade traz, em sua proposta, a idealização de se desconstruir séculos de prática asilar a que crianças e adolescentes, considerados expostos, enjeitados, abandonados ou com seus direitos ameaçados ou violados, vêm sendo submetidos.

Medidas asilares para crianças iniciaram no Brasil colonial com a Roda dos Expostos - aparelho cilíndrico com um dos lados vazados que permitia o ocultamento da identidade daquele(a) que abandonava, sendo, inicialmente, o exposto a criança fruto de amores ilícitos. A proteção ao abandonado associava então a idéia de civilização, embutida na imagem de se acabar com o abandono nas vias públicas, à necessidade da manutenção da moral familiar colonial (GONÇALVES, 1987). Cuidadas pelas irmandades religiosas, a Casa dos Expostos começou a ser mudada de local a partir do século XIX, em parte devido ao aumento de abandonados por motivos econômicos, e também pela preocupação médico-higienista com a acentuada mortalidade infantil no Hospital Velho da Misericórdia onde era seu local inicial. A Roda perpassou a época colonial, imperial e republicana vindo apenas a ser extinta em 1950 (MARCILIO, 1997). Portanto, durante o período de um século e meio foi praticamente a única instituição de assistência à criança abandonada no Brasil. Além desta, havia a prática de criar filhos alheios que embora largamente difundida no Brasil, ocorria em escala menor à internação.

$\mathrm{O}$ aumento crescente de abandonados fez com que fossem sendo criados orfanatos e patronatos de caráter variado para substituir a Roda dos Expostos. Os grandes internatos de caráter benemérito criados desde os anos trinta adotaram como matriz de trabalho uma dupla perspectiva que justificava sua ação tanto pela proteção à criança das condições adversas das ruas e de suas famílias como pela proteção da sociedade do convívio com tais crianças (CARVALHO, 1993).

Contribuiu, para o aumento do número dos considerados abandonados, a ampliação do conceito de abandono trazido pelo $1^{\circ}$ Código de Menores em 1927. De acordo com a tendência humanitária da época, o $1^{\circ}$ Código de Menores teve como proposta superar a limitada perspectiva penal no tratamento das questões da infância pobre, e incorporar como sua função o provimento da assistência (JASMIN, 1995). Assim, o código introduziu uma nova prática que combinava proteção e controle penal, que tem permeado a atenção à criança no Brasil desde então. $\mathrm{O}$ Código ampliou assim as funções dos Juizados de Menores para cobrir os menores abandonados e os menores delinquentes, duas categorias que passariam a nomear os destinatários da lei.

O conceito de abandono passou a englobar aqueles na rua ou os negligenciados por seus pais. Em contrapartida, o Juizado de Menores passou a intervir na família, impondo normas e condições para pais e guardiães e determinando, em última instância, a suspensão ou a perda do pátrio poder (GALHEIGO, 1996). Igualmente, colocou-se o papel de criar as primeiras instituições para proteger e confinar crianças pobres, a saber o Abrigo de Menores, a Casa Maternal Mello Mattos, a Escola de Reforma João Luiz Alves, o Recolhimento Infantil Arthur Bernardes e a Casa das Mãezinhas (ALVIM; VALLADARES, 1988). Entretanto, somente em 1941 que a iniciativa do Estado torna-se visivelmente representada na forma de um único Serviço de Assistência ao Menor, conhecido como SAM. Subordinado ao Ministério da Justiça e com algumas ligações com o Juizado de Menores na capital, o papel de SAM podia ser claramente compreendido como o de controlar a criminalidade juvenil. O SAM, criado depois de 20 anos de debate, tornou-se a primeira intervenção do Estado dirigida à criança pobre. Sua principal função foi prover internação para crianças e adolescentes na rua ou abandonados e para infratores. Entretanto, ao ser localizado no Rio de Janeiro, então capital do país, o SAM funcionou mais a nível local do que nacional, não podendo verdadeiramente ser reconhecido como foro de uma política nacional (GALHEIGO, 1996).

Mesmo antes do regime militar já se acreditava na exaustão dos procedimentos de proteção à infância. No início dos anos 50, o SAM foi severamente criticado por corrupção, negligência e crueldade para as crianças e jovens internados em suas dependências. $O$ pedido de sua extinção levou em 1956 à elaboração do projeto de criação de um Conselho Nacional para o Bem-Estar do Menor por beneméritos e segmentos da Igreja 
Católica. Contudo, atrasos em sua aprovação parlamentar o impediram de ser implementado.

Com o golpe militar em 1964, a idéia de um Conselho Nacional retornou sob a forma de uma Fundação, que inicialmente manteve as premissas iniciais do projeto anterior. Entretanto, tal proposta foi se modificando e assumindo as características particulares dos diferentes momentos do regime militar ao longo dos 26 anos que durou a Fundação Nacional do Bem-Estar do Menor (FUNABEM) e a Política Nacional do Bem-Estar do Menor (PNBEM) (GALHEIGO, 1996). Foi na primeira fase da PNBEM (de 1964 a 1979), quando ocorreu a consolidação institucional da política, que se deu a difusão de suas idéias pelo país e a criação de seus braços de implementação nos estados da federação - as Fundações Estaduais, que apesar de usarem siglas diferentes, passaram a ser largamente conhecidas, principalmente no Estado de São Paulo, como FEBEMs. Nesse período, os gestores da PNBEM adotaram um discurso nacionalista reproduzindo o pensamento da Escola Superior de Guerra e passando a se referir ao problema do menor como um problema de segurança nacional.

Segundo Altenfelder, primeiro presidente da FUNABEM, o chamado problema do menor era o produto de famílias desorganizadas, falta de preparação dos jovens para o casamento e falta de educação familiar (ALTENFELDER, 1977). A solução de tais problemas, segundo ele, estava no fortalecimento da família através de uma política social orgânica. A família tornou-se, portanto, um importante ponto de referência para as propostas iniciais da política, a partir da qual duas abordagens emergiram: a primeira, com a ênfase em programas comunitários que ajudassem a família a desempenhar seu papel e mantivessem suas crianças integradas na comunidade; e a segunda com a utilização da antiga idéia do Reformatório, embora que sob outra roupagem, para quando a família não tivesse condições de assumir sua função (GALHEIGO, 1996). Assim a FUNABEM delineou sua política para cuidar da criança marginalizada a partir de duas abordagens que dizia complementares: a preventiva e a terapêutica.

$\mathrm{Na}$ medida em que o processo de marginalização era visto como um problema que afetava a população como um todo, a abordagem preventiva passou a ser considerada como a mais viável já que poderia exercer influência sobre toda uma comunidade a baixo custo. A abordagem terapêutica, em contrapartida, veio a inaugurar uma nova era para a política da infância e da juventude no Brasil. A partir de então, problemas sociais passaram a ser considerados sob a perspectiva da intervenção terapêutica. Apesar do então chamado processo de marginalização social ser visto como um resultado das condições econômicas e sociais decorrentes do processo modernização do país, a busca de soluções não era pensada em termos de consecução de mudanças estruturais. Ao contrário, a resolução dos problemas sociais era esperada a partir de mudanças no indivíduo e sua família, levando a uma prática para a qual o foco no "estudo de caso" se adequava perfeitamente (GALHEIGO, 1996).

Desde então a infância e a juventude pobres passaram a ser estudadas, diagnosticadas e tratadas a partir do estudo-de-caso individual, de propostas de reeducação e internação. O problema do menor, de acordo com este ponto de vista, deveria ser cuidadosamente avaliado e o tratamento ser ministrado por equipe multiprofissional. O caráter científico impresso na proposta pretendia modernizar as práticas do velho reformatório. A fim de prover esse tipo de atendimento, uma significativa estrutura tecno-burocrática foi sendo gradualmente montada: assistentes sociais, psicólogos, psiquiatras, neurologistas, pediatras e professores passaram a ser os responsáveis pela avaliação, diagnóstico e acompanhamento pedagógico e terapêutico de crianças e adolescentes em regime de internação, assim como pelo envio de relatórios evolutivos para o então chamado Juiz de Menores (GALHEIGO, 1996). Tal intervenção era para ser de escopo limitado dado seu alto custo ou, nos termos da política, para que tivessem um efeito qualitativo (FUNABEM, 1973, 1976). Para o desenvolvimento da proposta foi criado o Centro Piloto da FUNABEM, na antiga Escola XV de Novembro no Rio de Janeiro, cuja finalidade expressa era de funcionar como um laboratório de métodos e técnicas, para a criação, implementação e avaliação de modelos de intervenção direta para o menor em processo de marginalização.

O modelo terapêutico propunha a identificação, classificação e distribuição de crianças e adolescentes conforme seu perfil biológico, psicológico e sociológico. Quando encaminhados pelo Juizado de Menores, deveriam ser admitidos em Centro de Recepção e Triagem (CRT), a porta de entrada para a institucionalização. Lá eram realizadas as primeiras avaliações da criança e do adolescente, seu diagnóstico psicológico e estabelecido seu programa de acompanhamento. Após o diagnóstico inicial, eram encaminhados para as Unidades Educacionais, organizadas por critérios tais como 
idade, sexo, conduta e motivo de internação (abandonados ou infratores) (VIOLANTE, 1982). Nãoé demais afirmar que o aparato de avaliação e tratamento criado, contribuiu para a medicalização e psicologização dos problemas sociais e para um processo de culpabilização da vítima. Ademais, o encaminhamento para Unidades Educacionais distribuídas em diferentes cidades (como no caso de São Paulo) levou à separação de irmãos, ao afastamento da família, a quebra de vínculos e a despersonalização da atenção. Entretanto, o que mais marcou tal empreendimento foram as violências empregadas no cotidiano, a negligência da atenção, a superlotação e inadequação das dependências, a disciplinarização e psiquiatrização dos internos (LUPPI, 1981; VIOLANTE, 1982; RIZZINI, 1985; JUNQUEIRA, 1986).

Se a PNBEM definia a ideologia a ser empregada para crianças e adolescentes pobres assim como suas metodologias de ação e as Fundações Estaduais cuidavam da prática asilar cotidiana, o aparato legal veio apenas a ser criado com a promulgação do $2^{\circ}$ Código de Menores em 1979. Ele veio oferecer um discurso de legitimidade à prática desenvolvida desde 1964 . O $2^{\circ}$ Código de Menores fazia uso de um discurso de antidiscriminatório para abolir a categorização inicial de menor abandonado e infrator (o termo delinqüente havia sido abolido pela Lei de Emergência em 1943). $\mathrm{O}$ argumento girava em torno da idéia que tais rótulos poderiam ser psicologicamente traumáticos e que o termo irregular era mais adequado, pois era o contrário de regular, isto é, o que estava de acordo com a norma jurídica (CAVALLIERI, 1976). Assim, criou-se uma nova categoria, o menor em situação irregular, considerando-se como situações irregulares a pobreza, a violência doméstica, o perigo moral, a falta de representação legal, o desvio de conduta e a infração penal.

A Doutrina da Situação Irregular tornou-se influente na América Latina e constituiu-se numa solução de compromisso entre o uso do Código Penal, aplicado ao adulto, e a Doutrina da Proteção Integral cuja proposta seria a de garantir por lei a satisfação plena das necessidades da população jovem de forma universal (CAVALLIERI, 1976; JASMIN, 1985; PAULA, 1990; MENDEZ; COSTA, 1994). Em conseqüência, o $2^{\circ}$ Código acabou destinando-se aos jovens pobres e suas famílias, que eram considerados objetos de sanção legal ao invés de sujeitos de direitos sociais. Acabou assim por criminalizar a pobreza, punir a família pobre com a perda do pátrio poder e punir a criança e o adolescente com a vida asilar, mesmo que sob a retórica da prevenção e do tratamento.

Como tais medidas estavam sob a autoridade exclusiva do Juiz de Menores, o tempo de internação não era previamente estabelecido, tornando-se com freqüência uma medida permanente. O $2^{\circ}$ Código de Menores veio a dar sustentação legal à Política Nacional de Bem-Estar do Menor, contribuindo para sua implementação. No geral, ambos trouxeram a pobreza para controle judicial, levando à sua criminalização e à internação da população jovem pobre. Acabaram também contribuindo para o aumento nos níveis de perda do pátrio poder, abandono e institucionalização. Quer intencionalmente ou não, regulamentaram e reforçaram a divisão por classe social e ajudaram a estabelecer uma cidadania de segunda classe.

Os anos oitenta se caracterizaram pela discussão acerca dos direitos das crianças e adolescentes que culminaram com a explicitação de direitos universais para o conjunto da infância brasileira na Constituição promulgada em 1988. O Estatuto da Criança e do Adolescente, legislação ordinária que dá forma a tais princípios, traz a proposta de desconstruir as políticas e práticas anteriores. Quando em seu livro I apresenta os direitos fundamentais do universo da população infantojuvenil, ele vem a afirmar a Doutrina da Proteção Integral. Quando em seu Livro II ele vem a tratar da política de atendimento, das medidas de proteção e das medidas sócio-educativas ele vem a contribuir para a restruturação da política de atenção com recomendações que visem a qualificação das mesmas. Entretanto, apesar de serem até detalhadas, é a prática construída cotidianamente que pode dar substância e visibilidade a ações emancipatórias.

\section{As medidas de proteção e o abrigo segundo o ECA: dos princípios à realidade atual}

O Estatuto da Criança e do Adolescente combina, portanto, a introdução de mudanças legais com a apresentação de princípios que norteiem a melhoria da assistência oferecida e a reestruturação dos processos de formulação e implementação das Políticas para a Infância e a Adolescência.

A descentralização político-administrativa, já expressa no texto constitucional e regulamentada no ECA, leva à municipalização da política de atendimento que passa a ser formulada e implementada pelo Conselho Municipal de Direitos da Criança e do 
Adolescente. Cabe ao Conselho Tutelar, a verificação do cumprimento dos direitos da criança e do adolescente regulamentados pelo ECA. A legislação e a reestruturação política, portanto, inauguram uma nova experiência que é a do munícipio exercer o estudo de sua próprias demandas sociais, a formulação de uma política que atenda tais necessidades, e, por fim, a organização e fiscalização da assistência oferecida por entidades governamentais e não-governamentais. Tal tarefa tem se deparado com uma série de dificuldades que podem ser resumidas em cinco aspectos, a saber:

a. confusão de papéis, oscilação de interação (que se manifesta pela dinâmica eleitoral), falta de sintonia de agenda e conflitos de ordem variada entre o Executivo municipal eleito, que funciona sob a lógica de uma democracia representativa e o Conselho de Direitos, que funciona sob a lógica de uma democracia participativa;

b. a falta de experiência, preparo técnico e disponibilização de recursos para a realização de diagnóstico situacional do município e o conseqüente estabelecimento de diretrizes e estratégias de curto, médio e longo prazo através da hierarquização das demandas;

c. dificuldade em romper com a política de interesses local e com o legado assistencialista e corporativista das políticas locais;

d. falta de recursos para a implementação de programas;

e. falta de uma política de formação de recursos humanos.

Tais dificuldades manifestam-se em maior ou menor grau conforme a realidade da política local, a dimensão estratégica do município, o volume de demandas de caráter social, o grau de organização dos movimentos sociais locais e a capacidade de produção de recursos a serem utilizados.

A política de proteção municipal e a ação dos abrigos muito depende da dinâmica política do município, da sua rede de atenção, de sua capacidade de rompimento com práticas assistencialistas e proposição de ações alternativas. Um dos aspectos que têm prejudicado a política de abrigo é alto custo de manutenção de tais programas e a falta de uma rede municipal de serviços que dê suporte às necessidades dos abrigados. Segundo, é a dificuldade de se transformar a ação de entidades que têm atravessado décadas oferecendo atenção sob modelos assistencialistas e disciplinares. É mais fácil construir um equipamento novo do que desconstruir um antigo, fato este que depende de decisão política tanto do governo como do Conselho de Direitos.
$\mathrm{Na}$ verdade, o aumento da demanda e a escassez de recursos têm feito os abrigos trabalharem acima de sua capacidade física, material e humana. Esta escassez tem levado à uma política de recursos humanos insuficiente com cuidadores pouco qualificados, falta de pessoal técnico para lidar com o volume de situaçõesproblema no cotidiano e falta de investimento em formação continuada. Como a maioria dos abrigos são entidades não-governamentais e existe pouco dinheiro público sendo investido nos programas, percebe-se que o foco das preocupações da equipe dirigente dos abrigos é a busca de recursos. Isto faz com que venham a dispender tempo significativo em captação de recursos que garantam a sobrevivência básica, deslocando o esforço do trabalho que deveria ser dirigido ao abrigado. Em consequiência, há falta de recursos para manutenção do espaço físico e para atender às demandas cotidianas, seja de alimentação, transporte, medicação, vestuário, lazer ou gastos extras.

Isto faz com que os princípios recomendados pelo ECA assumam um segundo plano, quando na verdade eles deveriam ser os norteadores da ação. É preciso lembrar que não se trata apenas de discutir a política de abrigos do município mas as medidas de proteção que são propostas. Em seu Artigo no 101, o ECA declara que as medidas específicas de proteção são: o encaminhamento aos pais ou responsável, mediante termo de responsabilidade; orientação, apoio e acompanhamento temporários; matrícula e frequiência obrigatórias em estabelecimento oficial de ensino fundamental; inclusão em programa comunitário ou oficial de auxílio à família, à criança e ao adolescente; requisição de tratamento médico, psicológico ou psiquiátrico, em regime hospitalar ou ambulatorial; inclusão em programa oficial ou comunitário de auxílio, orientação e tratamento a alcoólatras e toxicômanos; abrigo em entidade e colocação em família substituta.

Deste artigo fica claro que a medida de abrigo é a sétima, ou melhor, a penúltima dentre as medidas previstas. Antes dela são recomendadas uma série de outras que pressupõem uma rede de atenção municipal de caráter intersetorial. Na medida em que investe-se de forma insuficiente nas políticas sociais básicas e em programas de apoio familiar e comunitário, é esperado que os problemas acabem assumindo um grau de seriedade maior que acaba culminando na retirada da criança ou do adolescente de sua família e seu encaminhamento para um abrigo. Tal fato só vem agravar a atenção municipal pois, como dito anteriormente, o abrigo é um equipamento social caro de ser mantido e sua ação eficaz pressupõe o suporte de uma rede de serviços, ironicamente a mesma que 
falhou na atenção que culminou no abrigamento.

Portanto, há que se afirmar que o primeiro princípio para o desenvolvimento do trabalho nos abrigos é o fortalecimento da rede social de suporte seja através da ação territorial intersetorial, da rede municipal de serviços e da rede social no seu sentido mais amplo, isto é, incluindo o fortalecimento dos laços sociais, comunitários e das redes de solidariedade. O segundo princípio fundamental é que o enfrentamento dos problemas sociais se dê a partir da concepção de direito social e não pela perspectiva assistencialista que vem da idéia de favor, e estimula uma dependência paternalista à entidade filantrópica. O terceiro princípio é o de humanizar e profissionalizar a atenção oferecida nos abrigos. Por mais que seja polêmica a afirmação do papel do técnico quando tanto tem se discutido sobre a monopolização que este tem feito do saber e do poder nas ações sociais e de saúde, é indiscutível que há uma necessidade premente de se evitar a compreensão do abrigo enquanto mero local de estadia e sobrevivência. A presença maciça de crianças e adolescentes vítimas de negligência e violência graves serve de amostra da complexidade da atenção requerida. Reduzir a atenção ao oferecimento de teto, roupa e comida é subestimar as graves implicações dos acontecimentos vividos por estas crianças para seu desenvolvimento saudável e resulta num sério desrespeito aos direitos humanos.

$\mathrm{O}$ abrigo não é uma medida restritiva de liberdade como o era na época da PNBEM e do $2^{\circ}$ Código de Menores. Portanto, o quarto princípio fundamental do abrigo é construção do espaço enquanto lar, lugar efetivo de acolhimento, proteção, continência e sociabilização. Para tal é fundamental considerarmos as recomendações previstas no Artigo $n^{\circ} 92$ do ECA que afirma a importância da preservação dos vínculos familiares e comunitários, o não desmembramento de grupos de irmãos e a participação na vida comunitária. Deve-se também oferecer um atendimento personalizado e em pequenos grupos que possibilite a entidade assumir o papel da família na educação dos seus membros. Deve-se evitar sempre que possível a transferência de abrigo para que a criança e o adolescente sinta aquele espaço como local de acolhimento, continência e crescimento. Portanto, a transferência e o desligamento não devem ser usados pela equipe e dirigentes da entidade como forma de punição, disciplinarização e controle da conduta dos abrigados. Igualmente, o desligamento do abrigo deve ser gradual e bem trabalhado, isto é, no sentido que o abrigado entenda os motivos e se sinta em condições de lidar com a mudança a se realizar.
Desconstruindo a prática asilar e construindo o abrigo: o papel do técnico e do terapeuta ocupacional na organização da vida cotidiana e no cuidado de situações especiais

Ao se construir a idéia de abrigo, a partir de uma perspectiva alternativa à asilar, é fundamental se pensar na característica de lar que ele deve assumir, assim como no perfil técnico das ações a serem desenvolvidas para que efetivamente ele cumpra sua função de proteção. Assumir as características de um lar implica que o abrigo tenha um número pequeno de crianças e adolescentes (de 10 a 20) de gênero e idade variados, garantindo assim a manutenção de irmãos juntos. O acolhimento e cuidado devem ser compatíveis com o de uma família, devendo se garantir um cotidiano em que as crianças e adolescentes venham a participar da rotina doméstica, que garanta o respeito às diferenças pessoais e de faixa etária. $\mathrm{O}$ ambiente deve garantir a personalização do espaço físico, do vestuário, a manutenção de objetos pessoais. Deve também ser garantida a inserção na comunidade com acesso à escola local, serviços de saúde e a atividades culturais, religiosas e esportivas desenvolvidas no território. Há que se compreender que o território de uma criança se expande conforme seu desenvolvimento físico, mental e social e que diferentes locais devem ser gradativamente incorporados.

O primeiro aspecto que deve ser abordado quando se discute a profissionalização do abrigo é o debate do papel do técnico nas instituições da violência (BASAGLIA, 1985). Aponta-se o fato dos técnicos terem historicamente se associado à equipe dirigente a favor da manutenção da ordem e da disciplina, passando a atuar como agentes de controle social. A própria atuação dos técnicos em inúmeros momentos das Fundações Estaduais do Bem-Estar do Menor apontam, no mínimo, para uma situação de subordinação, omissão ou conformismo a um sistema autoritário e repressor (LUPPI, 1981; VIOLANTE, 1982; RIZZINI, 1985; JUNQUEIRA, 1986). Como já descrito acima, a introdução das equipes multiprofissionais nos anos setenta e a atenção em torno do estudo de caso contribuíram para uma visão distorcida dos problemas sociais, levando a sua psicologização e medicalização.

Portanto, quando se fala em trazer elementos técnicos para a área é importante que esteja claro que trata-se de uma ação emancipatória, onde o técnico venha oferecer seu conhecimento para a melhoria da atenção oferecida. Busca-se assim ajudar os abrigos a superar a abordagem do cotidiano e seus conflitos sob 
a perspectiva de um senso comum impregnado de disciplina, ameaças, da ainda existente palmada educativa, da dicotomia bom menino-mau menino ou de visões doutrinárias.

Outro aspecto interessante a ser discutido é da viabilidade de se ter uma equipe interdisciplinar nos abrigos, principalmente nos pequenos (com número de 10 a 20 abrigados). Na medida em que estes recursos são caros, seria interessante se pensar em equipes municipais itinerantes, equipes de referência e ou programas de supervisão institucional. Tais ações poderiam ser coordenadas pelas Secretarias de Ação Social dos municípios da mesma forma que ocorrem programas similares nas áreas da Educação e da Saúde.

O terapeuta ocupacional apesar de, em determinados momentos históricos, ter participado de entidades que ofereciam internação, apenas recentemente começa a ser convidado a ingressar nas equipes de abrigo (PINTO, 1977; GALHEIGO, 2003a). Sua ação varia conforme a proposta institucional, a forma da organização e divisão do trabalho dentre da equipe multiprofissional. Como já dito acima, as ações inter e transdisciplinares mostram-se mais pertinentes aos modelos de atenção contemporâneos; entretanto, depende do projeto institucional a definição de suas formas de ação. A construção coletiva de um projeto de abrigo é de caráter interdisciplinar. É fundamental que profissionais de diferentes formações venham contribuir para elaboração de um projeto de atenção que contemple ações territoriais, institucionais, familiares, grupais e individuais. As ações territoriais devem buscar a realização de parcerias locais e iniciativas para a integração comunitária. Devem ter como meta participar da criação de uma rede de atenção à criança e ao adolescente no município, ao mesmo tempo, que dirigir as demandas para este rede com a finalidade de demonstrar a necessidade de sua estruturação. As ações institucionais devem buscar a organização de uma vida cotidiana mais saudável onde os conflitos institucionais rotineiros possam ser mais adequadamente solucionados e a rotina institucional seja rica em experiências e flexível no funcionamento. Igualmente, tal projeto deve contemplar a formação continuada dos cuidadores, oferecendo elementos que os auxiliem a lidar com situações mais difíceis.

A ação junto às famílias das crianças abrigadas é um trabalho delicado que implica em um equilíbrio entre possibilitar a manutenção dos laços familiares e o estabelecimento de vínculos mais saudáveis que possam permitir o retorno da criança a sua família nuclear ou ampliada. Por outro lado, cabe a proteção à criança daquelas famílias cujo a característica e o grau de violência limitam significantemente as possibilidades de restabelecimento sequer de contato.

$\mathrm{O}$ atendimento grupal e individual idealmente deve ser evitado e os abrigados que necessitem ajuda terapêutica devem ser encaminhados para equipamentos da rede. Entretanto, a falta frequente de recursos na rede, dificuldades de transporte, número escasso de cuidadores que possam se deslocar e número acentuado de abrigados requerendo cuidados especiais são fatores que acabam determinando o oferecimento de intervenção terapêutica dentro das dependências do abrigo. Trabalhos grupais que venham a trabalhar o fortalecimento dos vínculos ou facilitar a dinâmica operativa do cotidiano institucional são iniciativas que devem ser incentivadas. Atendimentos individuais que contribuam para a comunicação, expressão e a elaboração dos conflitos da população abrigada devem ser também considerados. Seja qual for a opção, isto é, por encaminhamento para a rede de assistência ou acompanhamento grupal ou individual na instituição, é fundamental que seja elaborado um plano personalizado para cada abrigado, na medida em que as circunstâncias e o tempo de abrigamento pode variar enormemente. É essencial a manutenção de prontuários com informações sobre o desenvolvimento, fotos, eventos importantes, particularidades das crianças e adolescentes abrigados, já que estes serão, por vezes, os únicos registros permanentes das histórias destas crianças.

Portanto, é premente a necessidade do desenvolvimento de projetos de profissionalização da área, com qualificação e capacitação dos cuidadores e gestores, que reverta o caráter assistencialista que a maioria dos abrigos vem ainda assumindo. Para tal, é necessário o desenvolvimento de uma política de recursos humanos que garanta seleção criteriosa de cuidadores e equipe técnica, formação continuada e supervisão técnica do trabalho realizado.

Um abrigo, em sua implantação ou reestruturação deve preocupar-se com a elaboração de um projeto de funcionamento com princípios, estratégias, dinâmica de funcionamento e recursos humanos e materiais cuidadosamente delineados. Deve buscar discutir e elaborar estratégias para lidar com as situações-limite cotidianas e com momentos críticos em que a criança possa sentir mais a ausência da família, tais como a hora do banho e dormir, fins de semana, aniversários, festas e feriados. O momento da visita de familiares, igualmente crítico, deve ser preparado e acompanhado com cuidado, garantindo-se sempre a presença dos cuidadores após seu término. O abrigo 
deve ter claramente estabelecidos e frequentemente avaliados os procedimentos de recepção, acolhimento e desligamento, já que a chegada ao abrigo assim como a saída são momentos cruciais no processo de proteção à criança. $\mathrm{O}$ estabelecimento de grupos de discussão do cotidiano institucional com gestores, cuidadores e abrigados (dentro de suas possibilidades cognitivas) são valiosos para a resolução das situações do dia-a-dia. Tais grupos possibilitam o esclarecimento de conflitos cotidianos e a resolução dos mesmos de forma mais consensual. No grupo de discussão crianças e adolescentes devem participar da elaboração das normas cotidianas que regem o abrigo de forma democrática, participativa e esclarecida. Este processo possibilita a aprendizagem das convenções sociais não como o cumprimento de determinações autoritárias dos dirigentes mas como parte da construção de uma vida saudável onde a livre expressão e a justiça social são princípios essenciais.

\section{CONCLUSÃO}

A ação nos abrigos deve ser fortalecida e uma equipe interdisciplinar tem muito a contribuir com a qualificação do trabalho. O terapeuta ocupacional é um profissional que por se preocupar com o cotidiano e o fazer humano pode vir a ter uma participação significante na melhoria da atenção oferecida. Entretanto, para se descontruir o modelo asilar, disciplinar e/ou assistencialista ainda frequentemente encontrado há que se investir em entender quais foram os erros históricos na atenção à criança e ao adolescente e procurar formas alternativas de intervenção.

GALHEIGO, S. M. The shelter for children and adolescents: considerations on the role of the occupational therapist. Rev. Ter. Ocup. Univ. São Paulo, v. 14, n. 2, p. 85-94, maio/ ago. 2003.

\begin{abstract}
This article addresses the role of occupational therapists in shelters for children and adolescents. It introduces the shelter both as a protection procedure established by law, the Statute of the Child and the Adolescent, and a refuge whose proposal and dynamics still need improvements. It starts by making a historical review of care received by the abandoned children since colonial times. This work makes also considerations about the action occupational therapist may undertake and raise limit-situations which have to be overcome.
\end{abstract}

KEY WORDS: Occupational therapy/trends. Constitution and bylaws. Refuge. Child, institucionalized. Adolescent, institucionalized.

\title{
REFERÊNCIAS
}

ALTENFELDER, M. Bem-estar e promoção social. São Paulo: Governo do Estado de São Paulo, Secretaria de Promoção Social, Assessoria de Comunicação Social, 1977.

ALVIM, R.; VALLADARES L. Infância e sociedade no Brasil: uma análise da literatura. Rio de Janeiro: BIB, 1988. Cap. 26, p. 3-37.

BASAGLIA, F. A instituição negada. Rio de Janeiro: Graal, 1985.

CARVALHO, M. C. Trabalhando abrigos. São Paulo: CBIA/ IEE-PUC-SP, 1993.

CAVALLIERI, A. O direito do menor. Rio de Janeiro: Freitas Bastos, 1976.

FUNABEM. O menor - problema - social” e a ação da FUNABEM. Rio de Janeiro, 1976. p. 142.
FUNABEM. Política nacional do bem-estar do menor em ação. Rio de Janeiro: FUNABEM, 1973. p. 302.

GALHEIGO, S. M. Projeto terapia ocupacional para crianças e adolescentes (TOCA). Campinas: PUCCampinas, 2002. (Mimeografado).

GALHEIGO, S. M. Relatório de pesquisa 'pensando a rede de proteção especial: um estudo sobre a atenção à criança em situação de risco pessoal e social em Campinas'. Campinas: PUC-Campinas, 2003. (Mimeografado).

GALHEIGO, S. M. O social: idas e vindas de um campo de ação em terapia ocupacional. In: PÁDUA, E.; MAGALHÃES, L. (Org). Terapia ocupacional: teorias e práticas. Campinas: Papirus, 2003a. 
GALHEIGO, S. M. A transdisciplinaridade enquanto princípio e realidade das ações de saúde. Rev. Ter. Ocup. Univ. São Paulo, v. 10, n. 2-3, p. 49-54, 1999.

GALHEIGO, S. M. Juvenile policy-making, social control and the state in Brazil: a study of laws and policies from 1964 to 1990 . Tese (doutorado) - Inglaterra: University of Sussex, 1996.

GALHEIGO, S. M. Relatório de trabalho de extensão no Externato São João (em associação com a disciplinas Prática Terapêutica Supervisionada II). Campinas: PUC-Campinas, 1999a. (Mimeografado).

GONÇALVES, M. A. Expostos, roda e mulheres: a lógica da ambiguidade médico-higienista. In: ALMEIDA, A. (Org.). Pensando a família no Brasil: da colônia à modernidade. Rio de Janeiro: Espaço e Tempo, 1987.

JASMIN, M. Para uma história sobre a legislação sobre o menor. Rio de Janeiro: NEAM/Depto. História-PUC/RJ, 1985. (Mimeografado).

JUNQUEIRA, L. Abandonados. São Paulo: Ícone, 1986.

LUPPI, C. Agora e na hora da nossa morte. O massacre do menor no Brasil. São Paulo: Brasil Debates, 1981.

MARCILIO, M. L. A roda dos expostos e a criança abandonada na história do Brasil. In: FREITAS, M. (Org.). História social da infância no Brasil. São Paulo: Cortez, 1997.

MENDEZ, E.; COSTA, A. Das necessidades aos direitos. São Paulo: Malheiros Editores, 1994.

PAULA, P. A criança e o adolescente: perspectivas da legislação ordinária. In: Cadernos FUNDAP. Infância, adolescência, pobreza: temas de um Brasil menor. São Paulo: FUNDAP, 1990. p. 36-45. (Cadernos FUNDAP, 18).

PINTO, J. Relato de uma experiência de Terapia Ocupacional no campo social. In: ENCONTRO CIENTÍFICO PAULISTA DE TERAPEUTAS OCUPACIONAIS, 5. São Paulo, 1977. Anais.

RIZZINI, I. A internação de crianças em estabelecimentos de menores: alternativa ou incentivo ao abandono? In: O menor em debate, espaço, cadernos de cultura. Rio de Janeiro: USU, 1985. p. 17-39.

VIOLANTE, M. O dilema do decente malandro. São Paulo: Cortez, 1982. 